\title{
La producción de un desaparecimiento. Verdad, aura y técnica en Walter Benjamin
}

\section{The Production of a Disappearance. Truth, aura, and technique in Walter Benjamin}

\author{
Mauricio Barría \\ Departamento de Teatro, Universidad de Chile \\ mbarriajara@hotmail.com
}

Resumen - El presente texto se propone analizar los conceptos de aura y técnica en Walter Benjamin, contrastándolos con las posiciones de Martin Heidegger, para pensar la imbricación de la obra de arte con el problema de la historia y la verdad.

Palabras clave: aura, técnica, obra de arte, verdad, Walter Benjamin.

Abstract - The following text proposes to analyze the concepts of Walter Benjamin, aura and technique, in contrast to those by Martin Heidegger, in order to think the interweaving of an artwork with the problem of history and truth.

Keywords: Aura, technique, artwork, truth, Walter Benjamin.

El problema del arte, de la obra y su circulación adquiere en Benjamin un carácter singular. No tanto por sus juicios y preferencias respecto a tendencias o formatos particulares, lo que constituiría el ejercicio habitual de una crítica que todavía considera el objeto artístico como uno autónomo de sus contextos sociales, sino precisamente por asumir esta última cuestión como un criterio radical. El lugar del arte como objeto de estudio (de crítica) se desplaza, tornándose él mismo en foco de otros objetos. El arte para Benjamin, más que la manifestación de una cierta cultura, es una herramienta preferencial desde la cual es posible analizar el verdadero objeto de estudio: la sociedad, la época, la historia y su vinculación con la política. Su lugar es, entonces, el lugar de una experiencia crítica, la experiencia misma que la modernidad ha encriptado, de tal suerte que la obra pasa a ser una alegoría de su propio contexto de producción: la modernidad permitirá desentrañar aquello que la época define de la obra, antes que lo que la obra define de la época.

Lo que el presente ensayo intenta despejar es cómo la noción de obra de arte de Walter Benjamin gesta un modo de entender la verdad: no tanto la obra considerada desde un interés estético, cuanto entendida como ejemplo ejemplar o imagen dialéctica de la paradoja que constituye lo moderno. 


\section{LA OBRA COMO HERRAMIENTA CRÍTICA}

[...] en cuanto sus imágenes (sus formas) representan la verdad de un mundo (su contenido), el arte actúa como síntoma de una verdad histórica y permite detectar en ella flancos vulnerables que posibiliten su cambio: el despertar de la conciencia colectiva y la posibilidad de redención.

Ticio Escobar, «La irrepetible aparición de la distancia»

Lo que interesará a Benjamin es la capacidad de la obra de arte de revelar el estado de la sociedad. Como él mismo sostiene:

Las relaciones sociales están condicionadas, según sabemos, por las relaciones de la producción. Y cuando la crítica materialista se ha acercado a una obra, ha acostumbrado a preguntarse qué pasa con dicha obra respecto de las relaciones de productividad de la época [...] Por tanto, antes de preguntar: ¿en qué condiciones está una obra literaria para con las condiciones de producción de una época?, preguntaría: ¿cómo es en ellas? (Tentativas sobre Brecht, 119).

A diferencia de la crítica convencional, que pone el foco en la dicotomía forma-contenido, y la crítica de izquierdas, en su equivalente tendencia-calidad, Benjamin propone resolver tales contradicciones a través de la noción de técnica. Pero lo que entiende por técnica el pensador alemán es bastante singular. Ésta no es definida aquí como un conjunto de procedimientos para realizar una tarea, lo que en cierta nomenclatura de moda se denominaría el know how, ni siquiera como un tipo de racionalidad instrumental que cosifica la relación con el mundo. La técnica es, por sobre todo, una óptica de análisis material de un fenómeno, en tanto dicho fenómeno se determina por estar (y ser) en ciertas y determinadas relaciones de producción o ser un tipo específico de relación de producción.

Mientras la pregunta de la crítica formalista es «en qué relación está la obra respecto a contextos productivos (para con las condiciones de producción)", lo que hay que preguntar, según Benjamin, es «cómo está en ellas». La obra desde una óptica material es inseparable de las condiciones de producción que la posibilitan, porque equivale desde ya a una clase de relación productiva, ella misma es imagen ejemplar de un proceso de producción que define a la sociedad completa.

Las condiciones de producción artísticas, entonces, no difieren formalmente de las condiciones de producción económicas de una sociedad, o por lo menos el análisis debiera evitar esa distinción. Lo novedoso no radica en esta aparente suplantación de lo artístico por lo ideológico, muy por el contrario, en esa nivelación de estatus es donde lo artístico algo puede decir a la comunidad. Así, lo artístico adquiere una función social, más precisamente un lugar político.

¿En qué sentido la técnica artística (o literaria) realiza esta transformación? En cuanto representa un modo de producción de resistencia a un modelo hegemónico, espiritualista antes que materialista, en el que estaría basado el capitalismo burgués que define la modernidad. En dicho modelo se privilegiaría la continuidad, la linealidad, la igualación, cuya imagen paradigmática, podríamos pensar, es la cadena de montaje. Experiencia 
que, en su focalización instrumental, no advierte lo fragmentario del proceso, ateniéndose a la descripción ordenada desde su culminación: el objeto fabricado.

El proceso, en cambio, en tanto proceso, es fragmentación e interrupción. Si apelamos a la notable idea del inconsciente óptico, lo que tenemos es que cada momento del proceso es eterno y finito a la vez. Cada momento es la posibilidad de otro resultado. La idea de montaje que tanto fascinó a Benjamin respecto al cine dice relación con la posibilidad de pensar ya no linealmente o alineadamente. Más que un concepto, la técnica es una imagen, con la cual se puede hacer presente la interrupción que constituiría una posibilidad revolucionaria de la historia. La técnica viene a romper las distinciones jerárquicas sobre las cuales se levanta el discurso artístico: las oposiciones entre forma y contenido, entre géneros, entre público y autor, entre experto y no iniciado. El fin del autor y su transformación en productor.

Pero lo que describe Benjamin no es un cambio cualitativo (o de especie), sino de punto de vista. La noción convencional de autor vendría a representar la figura del arte burgués como el producto de un inspirado, de un genio individual. Contra ello, el productor no se relaciona individualmente con algo singular, entendido como un ejecutante de técnicas que se disuelve en una cadena de montaje, en una relación de producción que, a la vez, es el elemento pivotal del capitalismo. El productor juega, como imagen dialéctica del proceso, en cuanto realiza el desmontaje de aquello que el propio capital pretende encriptar. No más autores, esto es, sujetos movidos por una idea o inspiración individual, sino productores, manipuladores de técnicas y materialidades, en fin, trabajadores. La individualidad trasiega en trabajo: «Es el trabajo mismo el que toma la palabra» (Tentativas sobre Brecht, 122). Ya no el sujeto individual, sino un sujeto histórico-político que es el sujeto de la revolución. Fin de las falsas antinomias:

sólo la superación en el proceso de la producción espiritual de esas competencias que, en secuela de la concepción burguesa, forman su orden, hará que dicha producción sea políticamente adecuada; y además dichas barreras competitivas de ambas fuerzas productoras, levantadas para separarlas, deberán quebrarse conjuntamente. El autor como productor experimenta - al experimentar su solidaridad con el proletariado-inmediata solidaridad con algunos otros productores que antes no significaban mucho para él $(127)^{1}$.

Cambia, por tanto, el concepto y la labor del artista, quien de protector de valores burgueses pasa a ser un gestor de transformaciones de los procesos de producción. La obra deja de ser ese objeto individual y válido por sí mismo, para transformarse en una técnica de transformación social. El artista como productor piensa la obra imbuida en esas relaciones y el arte mismo como un proceso. Incidiendo en esos procesos del propio arte, es decir, en la técnica artística (literaria, teatral, pictórica, etc.), modifica críticamente las estructuras reales de producción. Baste pensar aquí la función didáctica que aprecia Benjamin en el teatro épico brechtiano.

Y esto lo puede el arte, entendido desde la técnica, porque el modo de producción artístico, en especial aquél surgido bajo el signo de la reproductibilidad técnica, guarda una filiación alegórica con la propia idea de modernidad e historia que Benjamin se propone pensar, principalmente en las Tesis sobre la historia. Es inevitable no recordar aquí la propuesta heideggeriana de la esencia de la edad moderna como imagen, desarrollada

En la cita se refiere a la artificiosa diferenciación entre los oficios del periodista y el literato: entre el técnico operador y el intelectual creativo. 
especialmente en «La época de la imagen del mundo», de 1938. En dicho texto, Martin Heidegger establecerá el vínculo esencial entre ciencia y subjetividad, cuyo fundamental eslabón será la noción de imagen. Modernidad, de ese modo, significa que: «El hombre pasa a ser aquel existente en el cual se funda todo lo existente a la manera de su ser y de su verdad» (79). Lo cual implica pensar al mundo en una relación de oposición respecto al sujeto, en la que el sujeto llega al dominio de él, a través de su interiorización total como imagen: "Re-presentar significa en este caso: llevar ante sí lo existente como un opuesto, referírselo - al que se hace la representación - y hacerlo volver a entrar en esta relación consigo como dominio decisivo. Cuando sucede eso el hombre se pone en imagen sobre lo existente» (81). O dicho de otro modo, pone la imagen sobre lo existente.

Entonces, porque la modernidad es representación del mundo, su carácter epocal está signado por la experiencia de la imagen, por la producción de la misma. No es raro por ello el privilegio de lo artístico al comenzar el siglo veinte, que queda emplazado históricamente en las vanguardias (Hobsbawm). El proceso de las vanguardias es de algún modo la realización total del mundo como imagen (Escobar, 177). Transversalización de lo estético en la política, en la cultura, en la totalidad de las relaciones sociales. El mismo Benjamin hace notar este fenómeno en el epílogo de «La obra de arte en la época de su reproductibilidad técnica»:

La proletarización creciente del hombre actual y el alineamiento también creciente de las masas son dos caras de uno y el mismo suceso. El fascismo intenta organizar las masas recientemente proletarizadas sin tocar las condiciones de la propiedad que dichas masas urgen por suprimir. El fascismo ve su salvación en que las masas lleguen a expresarse (pero que ni por asomo hagan valer sus derechos). Las masas tienen derecho a exigir que se modifiquen las condiciones de la propiedad; el fascismo procura que se expresen precisamente en la conservación de dichas condiciones. En consecuencia, desemboca en un esteticismo de la vida política (55).

Lo notable en todo esto es, sin embargo, que el fascismo es la contracara de otra cosa, es el producto paradójico de una sociedad cuyo valor central estaba basado en la libertad individual. Pero esta continua paradoja que plantea Benjamin no es otra que la que define a la propia modernidad como fantasmagoría y apariencia (véase especialmente Parque Central). La modernidad consistiría en la producción de lo que ella no es, es decir, en la producción de promesas de progreso, de un mejoramiento continuo de las condiciones de vida en consideración de un grado cada vez mayor de autonomía, libertad y autoconciencia del sujeto. La experiencia de la industrialización y la guerra refuerza esta contradicción con la que se inaugura el siglo XX. Producción de apariencias que, no obstante, sólo podrían despejarse o develarse en la misma acción productiva. He aquí la importancia de la alegoría y de la imagen dialéctica como «método» del pensamiento para Benjamin. De ahí también su interés por Baudelaire, el poeta de los tiempos modernos, el artista de la metrópolis, del tedio y de la prostitución.

Como sostiene Susan Buck-Morss, Benjamin consideraba la alegoría más que como un recurso estético, como una forma artística particular de comprender la verdad (Dialéctica, 32). La alegoría es, entonces, un recurso crítico a través del cual Benjamin pretende fundar otra forma de pensar filosófico: una filosofía del fragmento y de lo concreto, una filosofía que insiste en la fragilidad de lo real antes que en su falsa perpetuidad. De hecho, tal como expone en El Origen del drama barroco alemán, la gran diferencia entre el símbolo — recurso característico del Renacimiento-y la alegoría es la manera 
en que cada cual se relaciona con la temporalidad. Mientras en el primero se manifiesta la eternidad efímera de las cosas, en la segunda se petrifica el instante fugaz: «[...] en el símbolo, con la transfiguración de la decadencia, el rostro transformado de la naturaleza se revela fugazmente a la luz de la redención, en la alegoría la faccies hipocratica de la historia se ofrece a los ojos del observador como pasaje primordial petrificado. Todo lo que la historia tiene de intempestivo, de doloroso, de fallido, se plasma en un rostro o, mejor dicho; en una calavera» (159). El emblema típico del Barroco es precisamente la calavera, muestra de la decadencia de la vida humana, de su transitoriedad y de su corta duración. La alegoría también es la representación de una concepción de la historia decadente y negativa en la cual no existe la redención. Se entiende por ello la insistencia en el uso de la imagen en Las Tesis sobre la Filosofía de la Historia: «La verdadera imagen del pasado transcurre rápidamente. Al pasado sólo puede retenérsele como imagen que relampaguea en el instante de su cognoscibilidad, para nunca más ser visto" o «Articular históricamente el pasado no significa conocerlo como verdaderamente ha sido. Significa apoderarse de un recuerdo tal como éste relampaguea en un instante de peligro» (Benjamin, La dialéctica en suspenso, tesis V y VI, 51).

Imagen en vez de concepto. La opción por una escritura de la fugacidad, en contra precisamente de una escritura de la perpetuación y la conformidad. Sabemos — señala Jorge Michell- que Benjamin pretendía cuestionar el concepto dominante de la historia como continuum, fundada en la imagen del cauce, idea sostenida por el historicismo y que constituye el fundamento de la Historia Universal. Una visión que trata de interpretar el tiempo histórico como flujo ininterrumpido hacia el futuro y elabora en su propio devenir un núcleo significante que se traspasa de generación en generación como cultura. Una historicidad que busca redimirse en la idea de un continuo progreso hacia lo mejor y que ve en ese futuro la solución alienada de los males presentes. Pero para llevar a cabo esa crítica no basta con anteponer al concepto otro concepto: la función del intelectual es modificar materialmente el discurso. Un pensamiento crítico, de este modo, no sólo ejecuta su acción revolucionaria en términos de contenido (tendencias), sino también de técnica literaria. Crítico es escribir de un modo tal que haga acontecer la transformación de las relaciones de producción, rompiendo las falsas oposiciones en las que se ha levantado el pensamiento burgués. O mejor, reventándolas en una cierta economía del exceso, en una exacerbación de lo mismo, en una superproducción de apariencia.

Entonces, si la historia es producción de verdad, esto es, construcción de discurso o decurso, el arte como recurso crítico sería la producción de fragilidad y paradoja, es decir, producción de un desaparecimiento, como contraimagen del sentido moderno de la verdad como aparecer. Así, donde la modernidad pretende esclarecer, en la seguridad de una fragilidad olvidada, al modo de un concepto que ha olvidado su origen experiencial según Nietzsche, la escritura benjaminiana desea volver a producir la precariedad, la catástrofe en la que se funda toda experiencia del mundo:

Hay un cuadro de Klee que se llama Angelus Novus. En él está representando un ángel que parece como si estuviese a punto de alejarse de algo que mira atónitamente. Sus ojos están desmesuradamente abiertos, abierta su boca, las alas tendidas. El ángel de la historia ha de tener ese aspecto. Tiene el rostro vuelto hacia el pasado. En lo que a nosotros nos aparece como una cadena de acontecimientos, él ve una sola catástrofe, que incesantemente apila ruina sobre ruina y se las arroja a sus pies. Bien quisiera demorarse, despertar a los muertos y volver a juntar lo destrozado. Pero una tempestad sopla desde el Paraíso, que se ha 
enredado en sus alas y es tan fuerte que el ángel ya no puede plegarlas. Esta tempestad lo arrastra irresistiblemente hacia el futuro, al que vuelve las espaldas, mientras el cúmulo de ruinas crece ante él hasta el cielo. Esta tempestad es lo que llamamos progreso (Benjamin, La dialéctica en suspenso, 53-54).

Pero lo que se jugaría en estas reflexiones sobre el arte y la producción, o cuando menos aquello en lo que quisiera insistir, es el problema de la verdad de una crítica a la manera en que la ontología occidental ha comprendido la verdad como aparecer. $\mathrm{Y}$ es en ese momento donde aparece la noción de aura.

\section{EL AURA COMO FORMA DE LA VERDAD/HISTORIA}

"La obra de arte en la época de su reproductibilidad técnica», de 1936, es sin duda uno de los textos capitales de la reflexión estética contemporánea. En él Walter Benjamin se hace cargo conceptualmente de los desafíos que ha acarreado el desarrollo de las nuevas tecnologías visuales. Proponiéndose de alguna forma continuar el impulso crítico que las propias vanguardias habían anticipado años antes, el guiño benjaminiano ofrece un modo de comprender la actividad artística como acción política.

El punto es qué entendemos por política aquí. Es interesante recordar nuevamente el cuestionamiento que realiza el historiador Eric Hobsbawm, en relación con las expectativas y fracaso de las vanguardias: lo más notable en ello es el reconocimiento de la vanguardia como forma consumada de la modernidad. El fin de ésta coincide, entonces, con eso que Benjamín denominará la estetización de la política. Todo aquello que críticamente se propusieron los artistas, el cuestionamiento a la percepción y la ampliación de la misma, con el consiguiente desplazamiento del modo burgués del arte, será realizado, por el contrario, "[...] por intermedio de una combinación de la lógica de la tecnología y de la lógica del mercado masivo, es decir, la democratización del consumo estético. Y principalmente, por cierto, por el cine [...]» (34).

El punto de inflexión está en el desarrollo de las nuevas tecnologías de reproducción mecánica que, en el caso de Benjamin, implica por sobre todo una modificación de las relaciones de producción. De ese modo, el arte o la experiencia artística servirán a Benjamin como efecto alegórico, como «imagen dialéctica» para desentrañar lo propio de la vida moderna. Arte es, diríamos, un ejemplo, una imagen para comprender el dispositivo de mercado y mercantilización que define el mundo moderno, pero, a la vez, la imagen que permitirá desmontar las estructuras de apariencia que implican, en su modo de realidad, el surgimiento del fascismo. La cita a Marx con la que Benjamin inicia el prólogo de «La obra de arte...» es clarificadora:

Cuando Marx emprendió el análisis de la producción capitalista estaba ésta en sus comienzos. Marx orientaba su empeño de modo que cobrase valor de pronóstico. Se remontó hasta las relaciones fundamentales de dicha producción y las expuso de tal guisa que resultara de ellas lo que en el futuro pudiera esperarse del capitalismo. Y resultó que no sólo cabía esperar de él una explotación creciente agudizada de los proletarios, sino además el establecimiento de condiciones que posibilitan su propia abolición (cit. en Discursos interrumpidos, 17). 
Nos parece encontrar en esta última frase el asunto capital. Las mismas condiciones de explotación del capitalismo son las condiciones de su abolición, porque Benjamin entiende que la Modernidad que les dio lugar es un suceso apariencial, que se define por un carácter fantasmático y paradójico. Bajo esta lógica del efecto se despliega el argumento del texto. "La obra de arte ha sido siempre fundamentalmente susceptible de repetición» (Discursos interrumpidos, 18).

El aserto consiste en situar la cuestión de la preproducción como un fenómeno no desligado de la obra de arte, de tal suerte que será necesario distinguir entre reproducción de la obra y reproductibilidad técnica. El primer caso refiere primordialmente al surgimiento de las artes gráficas, entre las que la litografía tendría un lugar destacado. Benjamin sostiene que la experiencia del grabado producirá un primer desplazamiento en el que será posible distinguir el modelo de la copia. Es decir, por el desarrollo de las técnicas de reproducción gráficas, por primera vez podemos pensar la relación entre una copia y un original por vía precisamente de una falta: «Incluso en la reproducción mejor acabada falta algo: el aquí y ahora de la obra de arte, su existencia irrepetible en el lugar en que se encuentra» (20). La irrepetibilidad de la obra está determinada por el emplazamiento espacio-temporal que funciona como póliza de garantía de su autenticidad. La autenticidad es pues aquello que da valor de arte al objeto, permitiéndole distinguirse del conjunto de las meras cosas. Una obra de arte es algo único porque está emplazada, pero estar emplazado implica también una relación retrospectiva con el objeto y, por tanto, la carga histórica que lo constituye emblemáticamente: «La autenticidad de una cosa es la cifra de todo lo que desde el origen puede transmitirse en ella desde su duración material hasta su testificación histórica» (22). Emplazar es por ello fijar en la tradición, donde tradición significa aparecer cada vez como un aquí y un ahora, es decir, como presencia. Y eso es lo que se llamará aura.

La reproductibilidad técnica, precisamente, modifica las formas del aparecer del objeto y con ello sus relaciones de producción. En la reproducción el aparecer se constituye desde una negación (una reacción) frente a su otro, lo auténtico, porque la copia se define desde su original, mientras que en la reproducibilidad técnica ello no ocurre: «El ámbito entero de la autenticidad se sustrae a la reproducibilidad técnica - y desde luego que no sólo a la técnica-. Cara a la reproducción manual, que normalmente es catalogada como falsificación, lo auténtico conserva su autoridad plena, mientras que no ocurre lo mismo cara a la reproducción técnica [...] la reproducción técnica se acredita como más independiente que la manual respecto del original» (21).

Esa independencia viene a conmover radicalmente las relaciones de producción en las que estaban inscritas tradicionalmente las obras de arte. Tal conmoción es la pérdida del aura: es decir, el desarrollo de las tecnologías de reproducción visual es visto por Benjamin como un acontecimiento decisivo y consumatorio de la modernidad, porque la modernidad misma está determinada por la caída del aura. Modernidad es desaparecimiento de aquello que se define por su aparecer, desaparecimiento de la presencia —en palabras de Heidegger («La esencia de la técnica» y "Qué significa Pensar»)—, lo que equivaldría a decir huida del ser, retirada del ser como la época de la retirada. Pero es aquí donde cobra fuerza el aserto del inicio, pues la desauratización del objeto artístico reviste un cierto paralogismo.

Cuando Benjamin define aura como «manifestación irrepetible de una lejanía» (Discursos interrumpidos, 24), inscribe el problema en relación con una pérdida del carácter 
sagrado de la obra. La sacralidad ${ }^{2}$, definida como el emplazamiento en la tradición, se fractura por una doble aspiración: por una parte, el deseo de una reducción máxima de la lejanía y, por ende, acercamiento que implica democratización; y, por otra, masificación del espacio y el tiempo, que encontraría su fundamento en una cierta transformación del gusto: "Quitarle su envoltura a cada objeto, triturar su aura, es la signatura de una percepción cuyo sentido para lo igual en el mundo ha crecido tanto que incluso, por medio de la reproducción, le gana terreno a lo irrepetible» (Discursos interrumpidos, 25). Acercar es clausurar la lejanía, cercanía que corresponde a la disponibilidad del ahí de la cosa y que, tras una operación deselitizante, transforma el objeto aurático en objeto de consumo - en mercancía- .

Benjamin referirá una polarización entre el valor singular/cultura de lo aurático y el valor exhibitivo de la sociedad de consumo; una tensión entre aura y mercancía, un traspaso del valor de aura al valor de mercancía, en la cual cada una quedaría definida por su contrario, por de pronto, en términos de una negación. El punto es superar la negación, que es precisamente el límite de la experiencia de la reproducción manual. Antes que una tensionalidad, Benjamin entenderá que lo que hay entre ambos es una transitoriedad conducida por la noción de apariencia. La experiencia aurática, el aparecer irrepetible de esa lejanía, no es posible sino desde su caída. Es decir, la pérdida del aura es su propia condición de aparecimiento, en tanto que el proceso de mercantilización, de estetización del mundo se define por un aparecer radical, por una cierta auratización de la mercancía misma:

Por primera vez en la historia universal, la reproductibilidad técnica emancipa a la obra artística de su existencia parasitaria en un ritual. La obra de arte reproducida se convierte, en medida siempre creciente, en reproducción de una obra artística dispuesta para ser reproducida [...] Pero en el mismo instante en que la norma de la autenticidad fracasa en la producción artística, se trastorna la función íntegra del arte. En lugar de su fundamentación en un ritual aparece su fundamentación en una praxis distinta, a saber en la política $(27-28)$.

Aquí es donde el recurso crítico de la alegoría cobraría un pleno valor, puesto que lo alegórico podría ser pensado como la producción artificial de una apariencia, es decir, la producción de una apariencia que se sabe aparente. Lo alegórico es transitoriedad de la apariencia, en un doble sentido de finitud y movimiento (Escobar, 146). La permanente recurrencia de los motivos del coleccionista, del flaneur y la prostituta, como lo indica Buck-Morss, constituyen las imágenes ejemplares de este doblez paradójico.

Lo que ocurre finalmente es que la desauratización de la obra implica la auratización de la mercancía. Y el arte ¿cómo juega en ello? Si el autor debiera ser mirado como productor y si la obra de arte en la época de la reproducción técnica se ha liberado de su valor ritual para ser emplazada políticamente, si la obra de arte ha sido hasta ahora la alegoría de un proceso histórico, entonces la función medular del arte es la producción de esa operación paradójica, la producción de un desaparecimiento - caída- del aura. Aquello que ocurre producto del desarrollo del capitalismo debiera ser producido

Sagrado significa separado. En este sentido, la semejanza al planteamiento de Bataille es interesante. Éste, sin embargo, lee la pérdida como cierta estructura inmanente en la producción de lo sagrado y, en ese sentido, como un fenómeno fuera de la historia. 
técnicamente por el arte, a través de lo cual éste estaría reformando las relaciones de producción.

Quisiera, sin embargo, torcer la cuestión hacia aquello que estaría en la base de un planteamiento como el que se presenta, la crítica a una concepción de la verdad como aparecimiento, a partir de la vinculación entre aura y verdad.

La relación entre arte y verdad no es nueva. Por el contrario, se encuentra en los inicios mismos de la reflexión estética occidental y constituye, de cierto modo, su plataforma programática. La cuestión que subyace a ello es el claro privilegio de que gozaba la visualidad respecto a los otros sentidos, como modo de acceder a la realidad, propio de la cultura griega. Platón, al igual que sus contemporáneos, encuentra en la vista un tipo de acceso menos material y más completo. La mirada permite guardar distancia y observar el acontecimiento sin involucrarse, lo que hoy denominaríamos objetividad. La naturaleza como principio de orden pone ante los ojos su verdad y, como meros testigos inanes, traducimos tal orden a la lógica de las palabras. Contrariamente a lo que nos incitaría pensar su desdén por la sensibilidad, la operación platónica consistió en relevar esquemas visuales materiales por una batería de metáforas con las que explica aquello que estaría más allá o excedería la densidad ocular. El reconocimiento del límite de la sensibilidad no desmonta los principios jerárquicos y las lógicas de mando con los que los griegos habían concebido su mundo hasta ese momento. Tal vez sea ése el motivo por el cual un pensamiento como el de Platón tuvo tanta y tan rápida aceptación y se convirtió definitivamente en la biblia del nuevo saber filosófico.

Este suceso contrasta con la suerte que seguirán las investigaciones de Aristóteles. El argumento que frecuentemente se ha esgrimido para explicar el olvido en el que cayó la obra del pensador es su vinculación con el Imperio macedónico, pero cabe pensar que como extranjero, como un otro entre iguales, efectivamente haya alterado estructuralmente un supuesto cultural. Si para Platón el límite del conocimiento -y su posibilidad- se encontraba en el propio carácter visual de lo real, Aristóteles reconocerá que el límite del conocimiento - y su posibilidad - se encuentra más bien en las palabras, porque refieren pero no copian lo real, y ello porque son de una índole diversa. Mientras para Platón la palabra es imagen de lo real —su doble- que debe lograr ajustar(se) en todo momento (Cratilo), para el segundo es materia audible. Así, de alguna forma ésta se confronta antitéticamente cuando trata de fijar el acontecer visual. La palabra cobra entonces una autonomía que en Platón es inhallable, y esa autonomía, quizá, es lo que permite comprender algunas de sus posiciones en la Poética acerca de la innecesariedad del espectáculo para sentir el efecto trágico; o, lo más interesante, por qué la tragedia se independiza del deber de la verdad, con lo que logra constituirse en un saber político.

El modelo visual que instala el pensamiento platónico reduce la experiencia a una obligación de encontrar en todo un elemento de visibilidad y, por tanto, a entender la verdad como evidencia, la obviedad de lo puesto ante los ojos. El ideal de la vida es, pues, la contemplación del mundo en el que el mundo se revela en su profundidad o en la profundidad de su figura, mas no en su intimidad. Aunque eso sea precisamente una contradicción, la figura es aquello que niega toda intimidad y la sustituye por profundidad. La intimidad es aquello que se rehúsa a ser visto, la profundidad es aquello que escapa a ser visto, pero escapar significa extralimitar. La profundidad entendida como la grandeza, son las formas de lo sublime-visual. 
Contemplar será, entonces, despejar la apariencia para que aparezca lo real. Tal reiteración pone de manifiesto, así mismo, el carácter eminentemente estético que asume lo real para Platón. La realidad física es una mímesis de lo efectivamente real, es decir, de la apariencia auténtica: lo que Platón llamó Idea (eidos). De ese modo, la imagen no autentificada quedaría definida ontológicamente por el no ser. Una imagen es lo que no es, o sea, simulación, engaño o simplemente una representación. Así, el error de la poesía sería que no despeja, sino que duplica la apariencia, haciendo más difícil el acceso a lo auténtico. Este productor premeditado de engaños merece ser expulsado de la ciudad, no tanto porque represente un peligro moral, cuanto por su nula contribución a una economía de la acumulación en que producir es conducir ante la mirada (Heidegger, «El origen de la obra de arte»). El poeta no produce sino que reproduce, lo que claramente constituye un gasto innecesario para una comunidad.

De la misma manera, toda la obra de Heidegger estará atravesada por esa suposición:

La palabra techné nombra más bien un modo de saber. Saber significa haber visto, en el sentido más amplio de ver, que quiere decir captar lo presente como tal. Según el pensamiento griego, la esencia del saber reside en la aletheia, es decir, en el des-encubrimiento de lo ente. Ella es la que sostiene y guía toda relación con lo ente. Así pues, como saber experimentado de los griegos, la techné es una manera de traer delante lo ente, en la medida en que saca a lo presente como tal fuera del ocultamiento y lo conduce dentro del desocultamiento de su aspecto; techné nunca significa la actividad de un hacer («El origen de la obra de arte», 48).

Podríamos decir que la destrucción de la metafísica no es otra cosa que el desmontaje de esta relación con la apariencia. Heidegger se percatará de que lo que en un primer momento podría ser resuelto como diferencia ontológica supone toda la historia de Occidente como historia de la metafísica. «El Origen de la obra de arte» es por ello un lugar singular, pues la obra - como lo indica la cita- sería un epicentro de la producción de apariencia y, en cuanto tal, ganaría su lugar en la historia moderna.

En dicho texto, el problema de la verdad surgirá bajo el expediente de una descripción, a nuestro juicio un notable ejercicio fenomenológico con una pintura de Van Gogh, en la que, por cierto, Heidegger elude por completo la obra como soporte representacional, instalándola (en lo que ella es) como condición de apertura de lo existente: «Pero tal vez todas estas cosas sólo las vemos en los zapatos del cuadro, mientras que la campesina se limita sencillamente a llevar puestas sus botas [...] Ha sido la obra de arte la que nos ha hecho saber lo que es de verdad un zapato» $(27,29)$. Esa magistral descripción de los zapatos de Van Gogh culminará en la clásica formulación según la cual la obra de arte es la puesta en obra de la verdad de lo existente, es decir, en ella se patentiza la esencia de la cosa como acontecimiento. La obra, lejos de ser representación, muestra la propia mostración, su indole exhibicional: el claro como verdad. La exhibición, entonces, no del carácter representacional sino apariencial del mundo como presencia: «En la obra la que obra es la verdad, es decir, no sólo algo verdadero. El cuadro que muestra el par de botas labriegas, el poema que dice la fuente romana, no sólo revelan qué es ese ente aislado en cuanto tal — suponiendo que revelen algo-, sino que dejan acontecer al desocultamiento en cuanto tal en relación con lo ente en su totalidad» (46).

Pero lo que se pone en juego primordialmente en la verdad de la obra es, ante todo, una relación al ser en su carácter histórico. Y en ello radica la relevancia e incluso tal vez su superioridad con el pensar, que, para Heidegger, más bien parecería intemporal. 
La verdad se establece en la obra. La verdad sólo se presenta como el combate entre el claro y el encubrimiento en la oposición alternante entre mundo y tierra. La verdad, en tanto que dicho combate entre mundo y tierra, quiere establecerse en la obra. El combate no debe ser apagado ni concluido en un ente traído delante propiamente para este fin, sino que debe abrirse a partir de este ente. Siendo esto así, dicho ente debe albergar en su seno los rasgos esenciales del combate. En el combate se conquista la unidad de mundo y tierra. Al abrirse, un mundo le ofrece a una humanidad histórica la decisión sobre victoria y derrota, bendición y maldición, señorío y esclavitud. El mundo en eclosión trae a primer plano lo aún no decidido, lo que aún carece de medida y, de este modo, abre la oculta necesidad de medida y decisión (52).

La historia de la verdad es también la verdad de la historia. La historia de los apareceres que resisten en su ocultamiento (la época), que adquieren un rasgo en la rasgadura de la decisión que mide y limita lo indecidible e inmenso. Pero porque hay tal inmensidad, la historia logra dimensionarse, adquirir forma o figura histórica, en este caso, en la obra de arte, pero no sólo en ella, sino también en la fundación del Estado, o en el sacrificio esencial, o en el pensar que interroga el mundo. A dicha cuestión Heidegger la denominará instalación, el modo propio de ser del alumbramiento de la verdad ${ }^{3}$.

La verdad se instala a sí misma en la obra, en ese combate entre mundo y tierra, en el cual la obra, como cosa finita, logra hablar a la historia simultáneamente histórica y trascendentalmente. Esta lucha permanente entre mundo y tierra toma forma en la obra como indicación de destino de un pueblo y por ello la forma paradigmática de la obra es la poesía, cuya materia es el lenguaje, el cual, aunque finito, trasunta su instalación epocal como guarda del espíritu de un pueblo: "Siempre que acontece el arte, es decir, cuando hay un inicio, la historia experimenta un impulso, de tal modo que empieza por vez primera o vuelve a comenzar. Historia no significa aquí la sucesión de determinados hechos dentro del tiempo, por importantes que ellos sean. La historia es la retirada de un pueblo hacia lo que le ha sido dado hacer, introduciéndose en lo que le ha sido dado en herencia» (Heidegger, «El origen de la obra de arte», 61 y 64$)^{4}$.

La historia se funda en una cierta dialéctica del aparecimiento - una confrontación entre aparecer y desaparecer-. Una decisión deja ver lo abismante de lo indecidible. La abismal fragilidad en que tiene lugar una decisión. En ese sentido, tanto la imagen de la caída en Benjamin, como el abismante momento de la decisión de Heidegger coinciden en lo que llamaríamos una crítica a esa estructura del aparecimiento que definiría el concepto moderno de lo político. Tal idea adquiere en el pensador francés Jacques Rancière un tono terminante: «No hubo por tanto <estetización〉 de la política en la edad moderna, porque en su principio ésta es estética $»^{5}(79)$. Si la política es producción de aparecimiento, producción de visibilidad, en lo cual coincide plenamente con lo estético, ello significaría que la política se abre como aparecimiento de la verdad de la historia. Pero cuando

La verdad acaece solamente de suerte que se instituya a sí misma en la lucha y ámbito de juego que por ella misma se abre. Siendo la verdad lo antagónico de iluminación y ocultación, le es propio lo que llamamos aquí la instalación («Origen de la obra de arte», 51).

4 Es preciso advertir que la traducción de Rovira que ha servido de base para el actual trabajo ha sido cotejada y en algunos casos refundida con la de Helena Cortés y Arturo Leyte. En todo caso la numeración de página responde a la de éste.

5 Y más adelante sugiere: «[...] la democracia es el tipo de comunidad que se define por la existencia de una esfera de apariencia específica del pueblo. La apariencia no es la ilusión que se opone a lo real. Es la introducción en el campo de la experiencia de un visible que modifica el régimen de lo visible. No se opone a la realidad, la divide y vuelve a representarla como doble» (126). 
olvida que olvida o más bien no recuerda su olvido, olvida que la posibilidad de tal aparecer, de la instalación es una apuesta en el abismo de una decisión, en ese ocultamiento que supone la inflexión del tiempo, en definitiva olvida la fragilidad en la que se sustenta la historia, entonces adviene el fascismo o el pensamiento totalizante de la técnica.

Frente a ello, Benjamin propone el recurso alegórico como dispositivo crítico de esa lógica totalitaria de la apariencia, en tanto la alegoría sería un modo de producción en el que lo manifiesto es precisamente su artificiosidad. Pero en la alegoría lo que juega es el aniquilamiento del aura: «En Baudelaire el poeta por primera vez proclama su derecho a un valor de exhibición. Baudelaire fue su propio empresario. La perte d'auréole afecta primerísimamente al poeta» (Parque central, 16). Esto es, el develamiento del carácter inauténtico de toda construcción representacional o a la cual puede ser sometida cualquier obra bajo la lógica de la reproductibilidad técnica, en la cual queda desemplazada, es decir, pierde el origen que la autentifica: «La catedral deja su emplazamiento para encontrar acogida en el estudio de un aficionado al arte; la obra coral, que fue ejecutada en una sala o al aire libre, puede escucharse en una habitación» (Discursos interrumpidos, 22).

Así, el acontecer productivo de esa pérdida es, a su vez, la posibilidad de la experiencia de lo aurático; en cuanto que el aura sólo se experimentaría en su desaparecimiento, en la caída de la historia, en lo abismante o en lo perplejante de la catástrofe. Es pensable el aura ahí donde ha caído en el valor exhibitivo del arte, y es esto lo que pone en marcha la técnica como lugar crítico: «El mundo de los objetos en torno al hombre toma cada vez descaradamente la expresión de la mercancía. Simultáneamente la publicidad comienza a revestir de brillo el carácter mercantil de las cosas. A la transfiguración falaz del mundo mercantil se viene a contraponer su dislocación en lo alegórico. La mercancía busca mirarse a sí misma a la cara. Celebra su encarnación en la puta» (Parque central, 22).

La recuperación crítica de lo aurático en el arte sería, pues, la producción de un desaparecimiento, al contrario de la política sería la producción del espacio vacío, del silencio del límite sináptico entre los cuerpos ${ }^{6}$. Esta torsión planteada por Benjamin traza finalmente una nueva relación con la verdad y la historia, en la que, a nuestro juicio, vuelve a ser pensable la cuestión de la ficción que, en tanto ficción, quedaría determinada como producción de una ausencia. La historia sucedería ahí donde todo está perdido, en el límite de la imagen, es decir allí donde no hay nada más que ver, donde sólo es posible una recuperación ficcional del acontecimiento.

\section{REFERENCIAS}

Benjamin, Walter. «El autor como productor». Tentativas sobre Brecht. Madrid: Taurus, 1998. Medio impreso.

- «La obra de arte en la época de su reproductibilidad técnica». Discursos Interrumpidos I. Madrid: Taurus, 1989. Medio impreso.

6 Sería interesante volver a pensar la definición de lugar que Aristóteles desarrolla en Física IV, 5, como aquel espacio que media entre el cuerpo contenido y el cuerpo contenedor. 
. El origen del drama barroco alemán. Madrid: Taurus, 1990. Medio impreso.

- La dialéctica en suspenso, fragmentos sobre historia. Traducción, introducción y notas de Pablo Oyarzún Robles. Santiago: Ediciones de La invención y la herencia, Lom-ARCIS, 1995. Medio impreso.

. Parque central. Traducción e introducción de Ronald Kay. Santiago: Ediciones Metales Pesados, 2005. Medio impreso.

Buck-Morss, Susan. Dialéctica de la Mirada. Madrid: Ed. Visor, 1995. Medio impreso. . «La revolución de los vagabundos». Revista N 107, 15 de octubre de 2005. Medio impreso.

Escobar, Ticio. «La irrepetible aparición de la distancia. (Una defensa política del aura)». El arte fuera de sí. Asunción: Museo del Barro/Fondec, 2004. Medio impreso.

Heidegger, Martin. «La época de la imagen del mundo». Sendas perdidas. Buenos Aires: Ed. Losada, 1960. Medio impreso.

. «El origen de la obra de arte». Sendas perdidas. Buenos Aires: Ed. Losada, 1960. Medio impreso.

. «La esencia de la técnica». Conferencias y artículos. Barcelona: Ediciones del Serbal. 1994. Medio impreso. . "Qué significa Pensar». Conferencias y artículos. Barcelona: Ediciones del Serbal. 1994. Medio impreso.

. Caminos de bosque. Traducción de Helena Cortés y Arturo Leyte. Madrid: Alianza, 1996. Medio impreso.

Hobsbawm, Eric. A la zaga. Decadencia y fracaso de las vanguardias del siglo XX. Barcelona: Editorial Crítica, 1998. Medio impreso.

Michell, Jorge. "La pequeña puerta. (Notas sobre filosofía de la historia e imagen en Walter Benjamin)». Revista Globalización (julio, 2002). Revista electrónica.

Rancière, Jacques. El Desacuerdo. Buenos Aires: Ediciones Nueva Visión, 1996. Medio impreso.

Recepción: 20 de enero de 2011

Aceptación: 4 de marzo de 2011 